REVIEW ARTICLE

\title{
A review of Dendromonocotyle (Monogenea: Monocotylidae) from the skin of stingrays and their control in public aquaria
}

\author{
Leslie A. Chisholm ${ }^{1}$, Ian D. Whittington ${ }^{1,2}$ and Andreas B.P. Fischer ${ }^{3}$ \\ ${ }^{1}$ Marine Parasitology Laboratory, School of Earth and Environmental Sciences, The University of Adelaide, North Terrace, \\ Adelaide, South Australia 5005, Australia; \\ ${ }^{2}$ Monogenean Research Laboratory, Parasitology Section, The South Australian Museum, North Terrace, Adelaide, South \\ Australia 5000, Australia; \\ ${ }^{3}$ Underwater World - Sunshine Coast, Parkyn Parade, Mooloolaba, Queensland 4557, Australia
}

Key words: Monogenea, Monocotylidae, Dendromonocotyle, aquaria, Dasyatidae, Taeniura meyeni

\begin{abstract}
Dendromonocotyle species (Monogenea: Monocotylidae) are the only monocotylids to parasitize the skin of chondrichthyan hosts. Currently 11 species are recorded from the skin of ray species in the Dasyatidae, Myliobatidae and Urolophidae. There have been increasing reports of Dendromonocotyle outbreaks on rays kept in public aquaria. This paper provides a broad review of Dendromonocotyle that should assist taxonomists and aquarists with species identification and help decisions on potential control methods for Dendromonocotyle infections. The taxonomy and host-specificity of Dendromonocotyle are discussed and a key to current species is provided. We summarise what little is known about the biology of Dendromonocotyle including egg embryonation and hatching, feeding, camouflage and reproduction. The efficacy of freshwater baths, chemical treatments and biological control measures such as the use of cleaner fish for Dendromonocotyle is also discussed. We demonstrate that effective control of Dendromonocotyle on captive rays is hampered by the lack of basic biological data on the life cycle of the parasites. A case history is provided outlining the success of a public aquarium (Underwater World, Mooloolaba, Queensland, Australia) in managing D. pipinna infections on captive Taeniura meyeni without chemical intervention simply by taking measures to reduce host stress.
\end{abstract}

Most Monogenea are recorded from the skin, fins and gills of teleost fish and only about 200 valid monogenean species in seven families (Acanthocotylidae, Amphibdellidae, Capsalidae, Hexabothriidae, Loimoidae, Microbothriidae, Monocotylidae) are known from various sites on chondrichthyans (Whittington and Chisholm 2003). In our experience, the infection intensity of monogeneans on wild sharks and rays is generally low. However, when elasmobranchs are kept in captivity, monogenean intensities can increase significantly due to their direct life cycle. In extreme cases, monogeneans can cause lesions at their attachment site which may result in the death of the elasmobranch either indirectly (via secondary infections) or directly (e.g. Poynton et al. 1997, Bullard et al. 2001).

The Monocotylidae comprises 23 genera and represents approximately $60 \%$ of all monogeneans recorded from elasmobranchs (Whittington and Chisholm 2003). This is a unique family because members can parasitize a broad diversity of sites on their chondrichthyan hosts including the skin, gills, nasal tissue, urogenital system and inner wall of the body cavity. Members of Dendromonocotyle are the only monocotylids to parasitize the skin. Recently there have been an increasing number of reports of Dendromonocotyle outbreaks on rays in public aquaria.
This review provides information on the taxonomy of Dendromonocotyle and a key to species to assist with identification. We highlight how little is known about the biology of Dendromonocotyle and how this lack of information impacts on the development of effective biological and chemical control measures. We then outline how one public aquarium, Underwater World, in Queensland, Australia, is managing Dendromonocotyle infections successfully without chemical intervention.

\section{TAXONOMY OF DENDROMONOCOTYLE}

Dendromonocotyle was proposed by Hargis (1955) and placed in its own subfamily, the Dendromonocotylinae, to accommodate a monocotylid species from the skin of Dasyatis say (Dasyatidae) captured in Alligator Harbor, Florida, USA. Ten additional species have since been described from the skin of dasyatid, myliobatid and urolophid rays (Table 1). Chisholm et al. (1995) synonymised Dendromonocotylinae with Monocotylinae based on the results of a phylogeny generated from morphological characters. This decision was later also supported by a phylogeny generated using large subunit rDNA sequences (Chisholm et al. 2001b). The

This paper was presented at the 6th International Symposium on Fish Parasites in Bloemfontein, South Africa, 22-26 September 2003.

Address for correspondence: L.A. Chisholm, Marine Parasitology Laboratory, School of Earth and Environmental Sciences, The University of Adelaide, North Terrace, Adelaide, South Australia 5005, Australia. Phone: ++61 88207 7302; Fax: ++61 882077222 ;

E-mail: chisholm.leslie@saugov.sa.gov.au 
Monocotylinae currently comprises three genera parasitic on rays: the monotypic Clemacotyle from the gill cavity, Dendromonocotyle (11 species) from the skin and Monocotyle (16 species) from the gills. The ventral surface of the haptor of all members of the Monocotylinae is divided into one central and eight peripheral loculi by septa armed with small sclerites (Fig. 1). Muscular papillae, which are also armed with small sclerites, extend into the marginal valve of the haptor (Figs. 1, 2). Dendromonocotyle is distinguished in part from other monocotylid genera by its habitat on the host (skin) and by the presence of highly dendritic intestinal caeca (Fig. 3). Clemacotyle australis, the only other monocotylid with dendritic intestinal caeca, is only reported from the inner wall of the gill cavity of the host and has additional finger-like dorsomarginal projections on the haptor that are absent in Dendromonocotyle (see Young 1967, Beverley-Burton and Whittington 1995).

Species within Dendromonocotyle can be distinguished from each other primarily by the morphology of the terminal sclerite on the haptoral papillae (Fig. 2) and by the morphology of the male copulatory organ, particularly the distal portion (e.g. Fig. 4) (see Chisholm and Whittington 1995). The presence or absence of small hamuli, the number of haptoral papillae and the number of sclerites on the papillae are also useful characters for species identification. The morphology of the male copulatory organ can change considerably as the parasite matures (see Chisholm and Whittington 1995, Chisholm et al. 2001a) therefore, it is important to use adult worms to identify species. Detailed terminology and illustrations of taxonomic characters used in the following key to species are provided in Chisholm and Whittington (1995), Chisholm et al. (2001a) and Chisholm and Whittington (2004) but Figs. 1-5 here provide a summary.

\section{Key to genera in the Monocotylinae and to adult species of Dendromonocotyle}

1 Haptor with one central and eight peripheral loculi, haptoral septa and marginal papillae armed with sclerites (e.g. Fig. 1). Intestinal caeca not dendritic. Usually parasites of gills. See Chisholm (1998) for key to species ........................... Monocotyle

- Haptor with one central and eight peripheral loculi, haptoral septa and marginal papillae usually armed with sclerites. Additional finger-like dorsomarginal projections on haptor present or absent. Intestinal caeca dendritic

2 Haptor with additional finger-like dorsomarginal projections; intestine without pigment, male copulatory organ not sclerotised. Parasites of inner wall of gill cavity. See Young (1967) and Beverley-Burton and Whittington (1995) for description of monotypic genus Clemacotyle

- Haptor without finger-like dorsomarginal projections; intestine usually contains brown/black pig- ment (e.g. Fig. 3); male copulatory organ sclerotised. Parasites of dorsal skin surface of dasyatids, myliobatids and urolophids ... Dendromonocotyle 3

3 Haptoral septa pairs two and three, not joining inner ring septum; outer ring septal sclerites absent; hamuli present ......................... D. californica

- All haptoral septa joining inner ring septum; outer ring septal sclerites present; hamuli present or absent .......................................... 4

4 Haptor with 42 marginal papillae ................ 5

- Haptor with 56 marginal papillae ................. 6

5 Hamuli present. Vaginal pore without spines ........ ......................................... D. ardea

- Hamuli absent. Vaginal pore armed with spines D. taeniurae

6 Hamuli present ................................... 7

- Hamuli absent .................................... 8

7 Marginal papillae with three sclerites including terminal sclerite. Male copulatory organ extending to level of testis ............................. D. colorni

- Marginal papillae with at least six sclerites including terminal sclerite. Male copulatory organ not extending to level of testis ................ D. akajeii

8 Male copulatory organ short, not extending past level of ejaculatory bulb ......................... 9

- Male copulatory organ extending past level of ejaculatory bulb ............................... 10

9 Male copulatory organ encircled by donut-shaped structure near distal end .............. D. centrourae

- Male copulatory organ without donut-shaped structure; distal end with small sclerotised ridges

D. pipinna

10 Distal portion of male copulatory organ without accessory filament; extensive musculature associated with ejaculatory bulb ......................... 11

- Distal portion of male copulatory organ with acces-

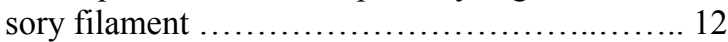

11 Male copulatory organ extends just posterior to ejaculatory bulb. Distal end of male copulatory organ with inflated, thick sclerotised walls ..........

D. torosa

- Male copulatory organ extends almost to haptor. Distal end of male copulatory organ with narrow sclerotised walls .......................... D. kuhlii

12 Distal end of ejaculatory duct within sclerotised male copulatory organ looping once, ending terminally ................................. cortesi

- Distal end of ejaculatory duct within sclerotised male copulatory organ not looping, ending subterminally

D. octodiscus

\section{BIOLOGY OF DENDROMONOCOTYLE}

Most Dendromonocotyle species are strictly hostspecific, but D. octodiscus has been reported from four host species (Table 1). Knowledge of the host taxon 

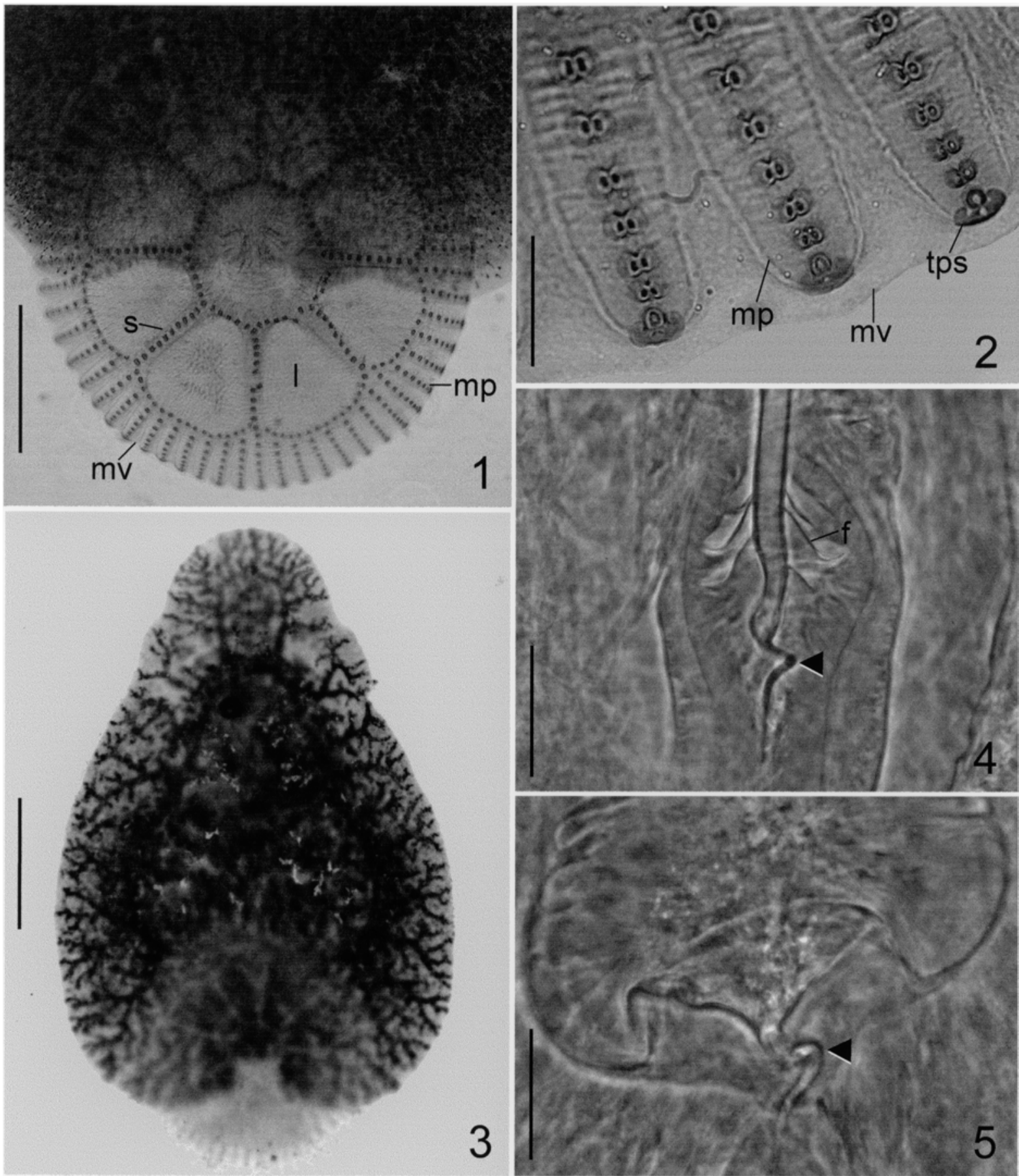

3

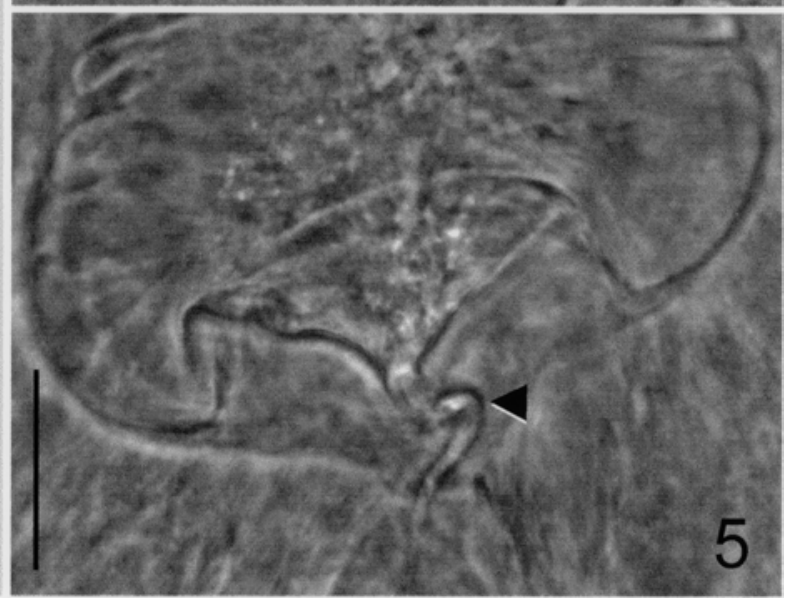

Figs. 1-5. Features of Dendromonocotyle Hargis, 1955. Fig. 1. Haptor of D. torosa. Septa (s), which are armed with small sclerites, divide the haptor into one central and eight peripheral loculi (l). Muscular papillae (mp), also armed with small sclerites, extend into the marginal valve (mv). Fig. 2. Enlargement of muscular haptoral papillae (mp) in marginal valve (mv) of $D$. torosa showing the morphologically distinct terminal papillar sclerite (tps). Fig. 3. Whole body of D. pipinna showing extensive dendritic intestinal caeca filled with dark pigment derived from the host's dorsal skin pigment. Fig. 4. Distal end of the sclerotised male copulatory organ of $D$. ardea. Note filament (f) and distinct loop (arrowhead). Fig. 5. Sclerotised proximal region of vagina of $D$. ardea. Note that the shape of the proximal loop (arrowhead) of the vagina corresponds closely to the shape of the distal loop of the male copulatory organ (see Fig. 4). Scale bars: Figs. 1, $3=500 \mu \mathrm{m}$; Fig. $2=100 \mu \mathrm{m}$; Figs. $4,5=50 \mu \mathrm{m}$. 
Table 1. An alphabetical list of Dendromonocotyle species.

\begin{tabular}{|c|c|c|c|}
\hline $\begin{array}{c}\text { Dendromonocotyle } \\
\text { species }\end{array}$ & Type host & Type locality & Author of original description \\
\hline D. akajeii & Dasyatis akajei & Toyama Bay, Sea of Japan, Japan & Ho and Perkins 1980 \\
\hline D. ardea & Pastinachus sephen & Heron Island, Queensland, Australia & Chisholm and Whittington 1995 \\
\hline D. californica & Myliobatis californica & $\begin{array}{l}\text { Shelter Island, San Diego Bay, } \\
\text { California, USA }\end{array}$ & Olson and Jeffries 1983 \\
\hline D. centrourae & Dasyatis centroura & Beaufort, North Carolina, USA & Cheung and Whitaker 1993 \\
\hline D. colorni & Himantura uarnak & Eilat Underwater Observatory, Israel & Chisholm et al. 2001a \\
\hline D. cortesi & $\begin{array}{l}\text { "mantarraya gris" } \\
\text { (species not identified) }\end{array}$ & $\begin{array}{l}\text { Bahia de los Angeles, } \\
\text { Gulf of California, Mexico }\end{array}$ & Bravo-Hollis 1969 \\
\hline D. kuhlii & Dasyatis kuhlii & Moreton Bay, Queensland, Australia & Young 1967 \\
\hline D. octodiscus ${ }^{1,2}$ & Dasyatis say & Alligator Harbor, Florida, USA & Hargis 1955 \\
\hline D. pipinna & Taeniura meyeni & $\begin{array}{l}\text { Underwater World, } \\
\text { Queensland, Australia }\end{array}$ & Chisholm and Whittington 2004 \\
\hline D. taeniurae & Taeniura grabata & Gorée, Senegal, Africa & Euzet and Maillard 1967 \\
\hline D. torosa & Aetobatus narinari & $\begin{array}{l}\text { Underwater World, } \\
\text { Queensland, Australia }\end{array}$ & Chisholm and Whittington 2004 \\
\hline
\end{tabular}

\footnotetext{
${ }^{1}$ Type species;

${ }^{2}$ Dendromonocotyle octodiscus has also been recorded from: Dasyatis americana (see Chisholm et al. 2001a), D. marmorata (see Euzet and Maillard 1967) and Urobatis jamaicensis (see Chisholm and Whittington 1995).
}

may assist with Dendromonocotyle species identifications but extreme caution is advised if using this approach because apparent strict host-specificity may be an artefact of the limited number of host species examined thus far for Dendromonocotyle. Furthermore, some hosts of Dendromonocotyle such as Aetobatus narinari and Himantura uarnak that were thought to have worldwide distributions are now believed to be species complexes (see Chisholm and Whittington 1998). If the host-specificity of Dendromonocotyle is strict but host species within a complex are misidentified, then many new species of Dendromonocotyle may be overlooked.

Our work suggests that species of Dendromonocotyle are likely restricted to the dorsal skin surface of rays, but some studies only identify the habitat as "skin" (Chisholm and Whittington 1995). The branched gut of Dendromonocotyle usually contains brown or black pigment (Fig. 3). Kearn (1979) provided evidence for $D$. kuhlii that this pigment is derived from the pigmented dorsal skin of the ray obtained when the parasites feed on host skin. Since the branches of the intestinal caeca extend throughout the body (excluding the haptor), the parasites are very difficult to see on the pigmented dorsal surface of the host. As a result, the camouflaged Dendromonocotyle are often only detected if skin scrapings are examined under a dissecting microscope or when infection intensities reach high levels.

Nothing is known about mating in Dendromonocotyle but the potential processes involved in mate recognition are fascinating. Chisholm and Whittington (1995) observed that for most species of Dendromonocotyle, the shape of the distal end of the male copulatory organ corresponds closely with the shape of the proximal portion of the vagina (cf. Figs. 4, 5). Chisholm and Whittington (1995) suggested that a lock-and-key method of species recognition might occur in Dendro- monocotyle given that recognition by chemical means is unlikely because of turbulence associated with living on the host skin surface. The transfer of sperm during mating appears to occur either directly by intromission or indirectly by spermatophore transmission. Spermatophores have been reported in D. akajeii (but see Chisholm and Whittington 1995), D. californica, D. centrourae, D. colorni, D. cortesi and D. octodiscus. How spermatophores are formed and transferred is unknown.

Dendromonocotyle species produce single tetrahedral eggs that have a small appendage at one pole. These eggs fall free of the host and because they are denser than seawater, they fall to the seabed. Eggs laid by adult $D$. ardea developed eyespots after three days and ciliated larvae hatched spontaneously after five days at $25^{\circ} \mathrm{C}$ (Chisholm and Whittington 1995). In D. kuhlii, eyespots appeared in developing embryos three days after laying and the free-swimming larvae emerged after five days at $22-25^{\circ} \mathrm{C}$ (Young 1967). Young (1967) did not state that the eggs required any special stimulation to hatch but Kearn (1986) noted that D. kuhlii eggs appeared to require mechanical disturbance for hatching to occur. Information on egg embryonation time, egg hatching and larval behaviour is not available for any other Dendromonocotyle species. Only the ciliated larva of D. ardea (see Chisholm and Whittington 1995) and D. kuhlii (see Young 1967) have been described. There are no data on larval longevity, host invasion behaviour, generation time or adult fecundity and longevity for any species of Dendromonocotyle.

\section{CONTROL OF DENDROMONOCOTYLE INFECTIONS ON RAYS IN CAPTIVITY}

Over the last decade, reports of Dendromonocotyle infections on rays in captivity have increased. Dendromonocotyle centrourae was described from the dorsal 
surface of Dasyatis centroura maintained at the New York Aquarium (Cheung and Whitaker 1993). Chisholm and Whittington (1995) reported D. octodiscus from Urobatis jamaicensis kept in a pet store and at the New York Aquarium. Dendromonocotyle colorni was described from Himantura uarnak held at Eilat Underwater Observatory in Israel (Chisholm et al. 2001a). Most recently, D. pipinna and D. torosa were described from Taeniura meyeni and Aetobatus narinari respectively, from Underwater World Aquarium in Mooloolaba, Queensland, Australia (Chisholm and Whittington 2004). Dendromonocotyle torosa has also been reported on $A$. narinari held at an aquarium supply company in Cairns, Australia (Chisholm and Whittington 2004). Unidentified species of Dendromonocotyle have also been reported on a specimen of $H$. uarnak kept in a public aquarium in Sweden and on specimens of Dasyatis brevicaudata kept in the Melbourne Aquarium in Melbourne, Victoria, Australia (Chisholm and Whittington, unpublished data).

Aquarists can choose to control Dendromonocotyle infections by a number of methods. Freshwater dips kill parasites quickly (e.g. Cheung and Whitaker 1993), but are stressful to elasmobranch hosts. Similarly, bathing the fish in chemicals such as formalin, praziquantel and trichlorfon also removes parasites efficiently (e.g. Thoney 1990, Thoney and Hargis 1991, Chisholm and Whittington 2002), but these treatments can also be stressful to fish depending on how animals are handled, bath duration and chemical concentrations. Furthermore, such treatments usually only provide temporary relief from parasite infections because when fish are returned to the display tank, parasite reinfection can occur quickly from Dendromonocotyle eggs and/or hatched larvae resident in the main tank system.

Complete elimination of Dendromonocotyle infections in aquaria is hindered by the lack of some very basic information about the life cycle of the parasites. As mentioned above, data on parasite generation time, adult fecundity and longevity, egg embryonation time, cues that trigger the monogenean eggs to hatch and information on larval longevity and infectivity and host invasion behaviour are lacking for most species. Without this fundamental knowledge, it is difficult to break the life cycle once the parasites have become established. Chisholm and Whittington (1995) demonstrated that eggs of $D$. ardea hatch spontaneously 5 days after being laid at $25^{\circ} \mathrm{C}$. However, they did not determine the longevity of the larvae although monocotylid larvae have been shown to live up to $55 \mathrm{~h}$ at $25^{\circ} \mathrm{C}$ (Chisholm and Whittington 2003). One appropriate protocol to eliminate $D$. ardea from rays kept in an aquarium at $25^{\circ} \mathrm{C}$ might therefore be as follows. 1) Isolate infected rays and remove parasites using two, 40 $\mathrm{h}$ treatments in $5 \mathrm{mg} / \mathrm{l}$ praziquantel (see Chisholm and Whittington 2002). 2) Keep rays in quarantine for at least 7 days ( 5 days for all eggs to embryonate and hatch; 2 days for hatched larvae to die) but preferably for 10-14 days to try and ensure any eggs and larvae in the system have hatched and died.

The crucial step in this protocol is to determine how long the rays must be isolated until all eggs and larvae resident in the main display tank have died. This is not easy to determine because egg embryonation time at the particular water temperature of the tank and factors that may trigger Dendromonocotyle eggs to hatch must be known. While $D$. ardea eggs appear to hatch spontaneously (Chisholm and Whittington 1995), there is an indication that $D$. kuhlii eggs may require mechanical disturbance (Kearn 1986), but more study to verify this is required. Eggs of other monogenean species that infect elasmobranchs are known to hatch in response to additional cues such as shadows cast by the host or to host skin secretions (see Whittington et al. 2000 for review). In the latter case, eggs can remain viable for long periods until they are stimulated to hatch by secretions from their specific host. For example, eggs laid by Acanthocotyle lobianchi (Acanthocotylidae), a skin parasite of Raja spp., were fully embryonated after 15 days at $13^{\circ} \mathrm{C}$, but the larvae within these eggs remained viable for 83 days and hatched only when exposed to host skin secretions (Macdonald 1974). For a public aquarium, keeping rays isolated for this length of time would present a large problem because animals on display represent their core business.

Another possible management method is biological control of Dendromonocotyle using cleaner organisms because skin-dwelling ectoparasites are readily accessible to predation. The effectiveness of cleaner fish in removing monogeneans has been demonstrated by a number of investigators (see Grutter 2002 for review). However, Kearn (1979) suggested that the camouflage provided by the pigment in the gut of $D$. kuhlii may protect the parasites from cleaner organisms. There is some evidence to support this suggestion. Snelson et al. (1990) studied the interactions between the bluehead cleaner wrasse (Thalassoma bifasciatum, Labridae) and the southern stingray (Dasyatis americana, Dasyatidae) at cleaning stations in the wild near Bimini, Bahamas. Cleaner wrasse spent 1-26 min cleaning the surface of the rays. After the cleaning events, no remnants of monogeneans were found in the stomach contents of the cleaner fish, but unidentified specimens of Dendromonocotyle were found on the rostrum, the posterior part of the disc and the base of the tail of the ray. Chisholm et al. (2001a) confirmed the identity of these specimens as D. octodiscus and established that dark pigment that may conceal the worms was present in the intestinal caeca. Therefore, it appears that T. bifasciatum may overlook camouflaged $D$. octodiscus on ray skin. Laboratory experiments have demonstrated that pigmented specimens of Benedenia lolo (Capsalidae) suffer less predation by the cleaner fish Labroides dimidiatus (Labridae) than unpigmented specimens (Grutter et al. 
2002). However, it has also been demonstrated that some species of cleaner fish are more efficient at detecting and removing monogeneans than other cleaner fish species. Cowell et al. (1993) found that the neon goby, Gobiosoma oceanops, and the cleaning goby, G. genie (Gobiidae), significantly reduced infections of the capsalid monogenean Neobenedenia melleni on cultured Florida red tilapia but $T$. bifasciatum did not. It is therefore also possible that a cleaner fish species other than $T$. bifasciatum, the species of cleaner wrasse investigated in the work of Snelson et al. (1990), might be more effective at removing Dendromonocotyle from rays.

\section{A CASE HISTORY: DENDROMONOCOTYLE PIPINNA ON CAPTIVE STINGRAYS, TAENIURA MEYENI}

As noted earlier, we have found that monogenean intensities are usually low on wild rays and that fish, when infected, appear to be healthy. The staff at Underwater World (UWW), Mooloolaba, Queensland, Australia observed that $D$. pipinna intensities remained at low levels on the single adult male and single adult female T. meyeni kept in the large tunnel public display tank (volume: 2.2 million 1) and that they required no treatment intervention. The female usually gives birth annually to up to 8 pups (Fischer, unpublished data). Immediately after birth, these juvenile rays are moved to and maintained in a smaller shallow display pool (6.7 $\mathrm{m} \times 3.5 \mathrm{~m} \times 0.8 \mathrm{~m}$ deep; volume: $\sim 18,7601)$. Up to four times daily, a staff member enters the shallow pool to feed the rays and present interactive talks to the public. During these presentations, members of the public are allowed to place their hands in the tank for the rays to brush against. In 2002, these juvenile rays developed $D$. pipinna infections that were directly correlated with tank water temperature (Fig. 6). Skin scrapings were used during routine veterinarian visits to estimate $D$. pipinna infection intensity. Using a stereo-dissecting microscope at $100 \times$ total magnification, intensity was graded from negative (no D. pipinna) to ++++ (five to ten specimens per visual field). The status of the parasite population was estimated by analysing the size of specimens in the scrapings. Presence of all large specimens indicated a no or low population growth rate; presence of all small juvenile specimens indicated that a recent wave of parasite recruitment had occurred and the presence of small and large specimens indicated infections with active turnover (Mogg, personal communication). During the winter months when water temperatures were below $25^{\circ} \mathrm{C}, D$. pipinna intensities were graded as negative to + (i.e. very few parasites) and consisted mainly of large specimens. However, parasite intensities increased during summer when water temperatures exceeded $25^{\circ} \mathrm{C}$ (January-April) and intensities were particularly high $(++++)$ when water temperatures approached $30^{\circ} \mathrm{C}$ (Fig. 6) for longer dura-

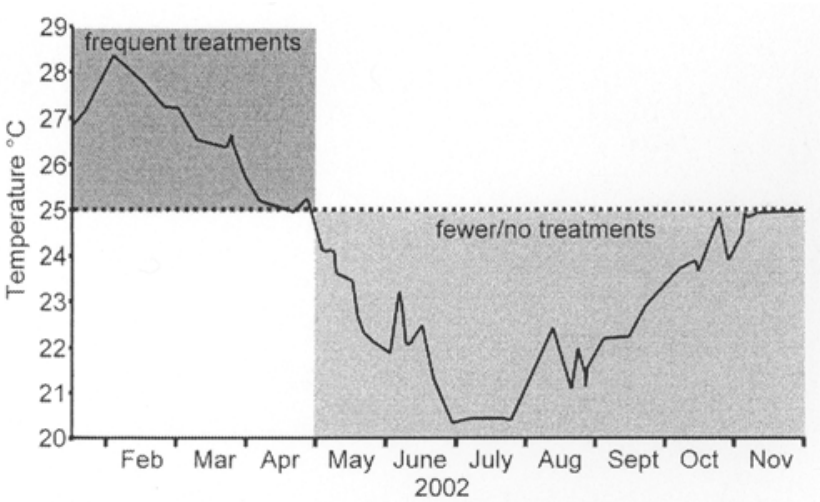

Fig. 6. Water temperature profile in the shallow display tank (volume: $\sim 18,760$ 1) at Underwater World, Mooloolaba, Queensland, Australia, February-November 2002. When water temperatures exceeded $25^{\circ} \mathrm{C}$, Dendromonocotyle pipinna intensities increased greatly and more frequent formalin baths and/or Lepidex ${ }^{\circledR}$ (= $500 \mathrm{~g} / 1$ trichlorfon) treatments were administered.

tions. The population comprised small and large specimens indicating active population turnover (adult parasites laying eggs and new recruits invading fish). At these times, the rays displayed skittish swimming behaviour and cloudiness on the dorsal surface around the eyes, spiracles and shoulder region. These symptoms and behaviour were attributed to high parasite loads and the rays were treated with formalin baths (20 $\mathrm{ml}$ of $37 \%$ formalin in 1001 seawater for 30-60 min; repeated after 14 to 20 days if necessary) and/or by dosing the entire shallow ray pool with Lepidex ${ }^{\circledR}(=500$ $\mathrm{g} / 1$ trichlorfon: $1 \mathrm{ml} \mathrm{Lepidex}{ }^{\circledR}$ to 20001 seawater $=9.38$ $\mathrm{ml}$ to 18,7601$)$. However, after treatments, the rays became reinfected rapidly by larvae hatching from $D$. pipinna eggs resident in the tank and over the course of summer, a number of heavily parasitized juvenile rays died. UWW staff suspected that repeated exposure to the chemicals may have weakened the rays so they could not cope with the parasite infections and that ultimately, it was the chemical treatments, not the parasites, which were responsible for host death. Post-mortems revealed extensive damage to the liver and kidneys of rays that could not be attributed to monogenean infections. This further supported the hypothesis that chemical treatment led to death. Therefore, UWW adopted an alternative approach to try to control $D$. pipinna infections based on observations that the two untreated adult specimens in the large tunnel display tank remained healthy and had low parasite levels year round even though water temperatures were the same as those in the small interactive display tank. Chemical treatments of juvenile rays were discontinued and protocols were initiated to minimise host stress. Ventilation in the pump plant room was increased to reduce tank water temperatures and the staff now do not enter the shallow display tank when water temperatures exceed 
$25^{\circ} \mathrm{C}$. This simple, non-invasive approach to manage $D$. pipinna infections on $T$. meyeni has been highly successful and since adopting this "stress reduction" regime, no juvenile specimens of $T$. meyeni have died at UWW. All rays now have only low infection levels of D. pipinna and in this case, the need to eliminate all parasites from the aquarium system appears unnecessary.

\section{FINAL REMARKS AND FUTURE DIRECTIONS}

This review has summarised knowledge on the taxonomy of Dendromonocotyle and we have highlighted what little is known about the biology of the genus. In aquaculture, integrated parasite management uses information on parasite biology and ecology so that any required chemical treatments are deployed strategically to minimise the number of applications and maximise overall efficiency (e.g. Pike and Wadsworth 2000). This integrated approach is currently not achievable for the treatment of Dendromonocotyle on captive stingrays because data on factors such as egg hatching, larval and adult longevity, fecundity and generation time are not available. Biological control of the ectoparasitic Dendromonocotyle using cleaner fish may be possible, but which cleaner fish species can detect camouflaged Dendromonocotyle needs to be determined. Using the case history at Underwater World, Mooloolaba, we have demonstrated that minimising host stress can effectively reduce Dendromonocotyle burdens on captive rays. However, the mechanisms underlying the relationship between stress and immunity in elasmobranchs and their susceptibility to monogenean infections are poorly understood. The role that temperature and chemical treatments play in this relationship is an obvious direction for future study on the control of monogenean infections on captive elasmobranchs. Various studies indicate that administration of anthelmintics orally via feed may be easier and less stressful to fish (e.g. Kim and Choi 1998, Duston and Cusack 2002). This provides perhaps an alternative avenue to pursue for the control of Dendromonocotyle and other monogeneans in public display aquaria.

Acknowledgements. We thank Brad McKenzie and Emily Thomas of Underwater World, Sunshine Coast, Mooloolaba, Queensland, Australia and Julian Baggio and Lyle Squire of Cairns Marine, Cairns, Queensland, Australia for their assistance. We are grateful to Dr Karin Mogg, Currimundi Veterinary Surgery, Queensland for her advice and assistance. We also thank the editors of Folia Parasitologica and Jo Van As for the invitation to contribute this manuscript to the Sixth International Symposium on Fish Parasites Special Issue. This study was funded by an Australian Research Council grant (no. A00104437) and an Overseas Conference Scheme Travel Award (to LAC), from the Faculty of Sciences of The University of Adelaide.

\section{REFERENCES}

BEVERLEY-BURTON M., WHITTINGTON I.D. 1995: Clemacotyle australis (Monogenea: Monocotylidae) from the white-spotted eagle ray Aetobatus narinari (Rajiformes: Myliobatidae) on the Great Barrier Reef: redescription, emended generic diagnosis, and oncomiracidium. J. Parasitol. 81: 616-625.

BRAVO-HOLLIS M. 1969: Helmintos de peces del Pacifico Mexicano. XXX. Descripción de tres monogéneos de la familia Monocotylidae Taschenberg, 1879. An. Inst. Biol. Univ. Nac. Autón. Mex. (Zool.) 2: 161-178.

BULLARD S.A., FRASCA S. Jr., BENZ G.W. 2001: Gill lesions associated with Erpocotyle tiburonis (Monogenea: Hexabothriidae) on wild and aquarium-held bonnethead sharks (Sphyrna tiburo). J. Parasitol. 87: 972-977.

CHEUNG P., WHITAKER B. 1993: A new dendromonocotylinid (monogenean) from the skin of the roughtail stingray, Dasyatis centroura Mitchill. J. Aquaricult. Aquat. Sci. 6: 63-68.

CHISHOLM L.A. 1998: A revision of Monocotyle Taschenberg, 1878 (Monogenea: Monocotylidae) with description of three new species from Australia. J. Nat. Hist. 32: 1259 1290.

CHISHOLM L.A., MORGAN J.A.T., ADLARD R.D, WHITTINGTON I.D. 2001b: Phylogenetic analysis of the Monocotylidae (Monogenea) inferred from 28S rDNA sequences. Int. J. Parasitol. 31: 1253-1263.

CHISHOLM L.A., WHEELER T.A., BEVERLEY-BURTON M. 1995: A phylogenetic analysis and revised classifica- tion of the Monocotylidae Taschenberg, 1879 (Monogenea). Syst. Parasitol. 32: 159-191.

CHISHOLM L.A., WHITTINGTON I.D. 1995: A revision of Dendromonocotyle Hargis, 1955 (Monogenea: Monocotylidae) with a description of a new species from Pastinachus sephen (Forsskål) (Myliobatiformes: Dasyatididae) from the Great Barrier Reef, Australia. J. Nat. Hist. 29: 1093-1120.

CHISHOLM L.A., WHITTINGTON I.D. 1998: Revision of Decacotylinae Chisholm, Wheeler \& Beverley Burton, 1995 (Monogenea: Monocotylidae) including the synonymy of Papillicotyle Young, 1967 with Decacotyle Young, 1967 and a description of a new species from Australia. Syst. Parasitol. 41: 9-20.

CHISHOLM L.A., WHITTINGTON I.D. 2002: Effectiveness of Praziquantel bath treatments for monogenean infections on the Rhinobatos typus. J. Aquat. Anim. Health 14: 230234.

CHISHOLM L.A., WHITTINGTON I.D. 2003: Invasion of the shovelnose ray (Rhinobatos typus) by Neoheterocotyle rhinobatidis and Merizocotyle icopae (Monogenea: Monocotylidae). Parasitology 127: 561-570.

CHISHOLM L.A., WHITTINGTON I.D. 2004: Two new species of Dendromonocotyle Hargis, 1955 (Monogenea: Monocotylidae) from the skin of Taeniura meyeni (Dasyatidae) and Aetobatus narinari (Myliobatidae) from aquaria in Queensland, Australia. Syst. Parasitol. 57: 221228. 
CHISHOLM L.A., WHITTINGTON I.D., KEARN G.C. 2001a: Dendromonocotyle colorni sp. n. (Monogenea: Monocotylidae) from the skin of Himantura uarnak (Dasyatididae) from Israel and a new host record for $D$. octodiscus Hargis, 1955 from the Bahamas. Folia Parasitol. 48: 15-20.

COWELL L.E., WATANABE W.O., HEAD W.D., GROVER J.J., SHENKER J.M. 1993: Use of tropical cleaner fish to control the ectoparasite Neobenedenia melleni (Monogenea: Capsalidae) on seawater-cultured Florida red tilapia. Aquaculture 113: 189-200.

DUSTON J., CUSACK R.R. 2002: Emamectin benzoate: an effective in-feed treatment against the gill parasite Salmincola edwardsii on brook trout. Aquaculture 207: 1-9.

EUZET L., MAILLARD C. 1967: Parasites de poissons de mer ouest-africains. VI. Monogènes de sélaciens. Bull. Inst. Fr. Afr. Noire, Sér. A., 29: 1435-1493.

GRUTTER A.S. 2002: Cleaning symbioses from the parasites' perspective. Parasitology 124: S65-S81.

GRUTTER A.S., DEVENEY M.R., WHITTINGTON I.D., LESTER R.J.G. 2002: The effect of the cleaner fish Labroides dimidiatus on the capsalid monogenean Benedenia lolo parasite of the labrid fish Hemigymnus melapterus. J. Fish Biol. 61: 1098-1108.

HARGIS W.J. Jr. 1955: Monogenetic trematodes of Gulf of Mexico fishes. Part V. The superfamily Capsaloidea. Trans. Am. Microsc. Soc. 74: 203-225.

HO J.-S., PERKINS P.S. 1980: Monogenea from fishes of the Sea of Japan. Part 1. Order Monopisthocotylea. Ann. Rep. Sado Mar. Biol. Stn., Niigata Univ. 10: 1-10.

KEARN G.C. 1979: Studies on gut pigment in skin-parasitic monogeneans, with special reference to the monocotylid Dendromonocotyle kuhlii. Int. J. Parasitol. 9: 545-552.

KEARN G.C. 1986: The eggs of monogeneans. Adv. Parasitol. 25: 175-273.

KIM K.H., CHOI E.S. 1998: Treatment of Microcotyle sebastis (Monogenea) on the gills of cultured rockfish (Sebastes schlegeli) with oral administration of mebendazole and bithionol. Aquaculture 167: 115-121.
MACDONALD S. 1974: Host skin mucus as a hatching stimulant in Acanthocotyle lobianchi, a monogenean from the skin of Raja sp. Parasitology 68: 331-338.

OLSON A.C. Jr., JEFFRIES M. 1983: Dendromonocotyle californica sp. n. (Monogenea: Monocotylidae) from the bat ray, Myliobatis californica, with a key to species. J. Parasitol. 69: 602-605.

PIKE A.W., WADSWORTH S.L. 2000: Sealice on salmonids: their biology and control. Adv. Parasitol. 44: 233-337.

POYNTON S.L., CAMPBELL T.W., PALM H.W. 1997: Skin lesions in captive lemon sharks Negaprion brevirostris (Carcharhinidae) associated with the monogenean Neodermophthirius harkemai Price, 1963 (Microbothriidae). Dis. Aquat. Org. 31: 29-33.

SNELSON F.F. Jr., GRUBER S.H., MURRU F.L., SCHMIDT T.H. 1990: Southern stingray, Dasyatis americana: host for a symbiotic cleaner wrasse. Copeia 1990: 961-965.

THONEY D.A. 1990: The effects of trichlorfon, praziquantel, and copper sulfate on various stages of the monogenean Benedeniella posterocolpa, a skin parasite of the cownose ray, Rhinoptera bonasus (Mitchill). J. Fish Dis. 13: 385389.

THONEY D.A., HARGIS W.J. Jr. 1991: Monogenea (Platyhelminthes) as hazards for fish in confinement. Annu. Rev. Fish Dis. 1991: 133-153.

WHITTINGTON I.D., CHISHOLM L.A. 2003: Diversity of Monogenea from Chondrichthyes: do monogeneans fear sharks? In: C. Combes and J. Jourdane (Eds.), Taxonomie, Écologie et Évolution des Métazoaires Parasites. (Livre hommage à Louis Euzet). Tome 2. PUP Perpignan, France, pp. 339-363.

WHITTINGTON I.D., CHISHOLM L.A., ROHDE K. 2000: The larvae of Monogenea (Platyhelminthes). Adv. Parasitol. 44: 138-232.

YOUNG P.C. 1967: A taxonomic revision of the subfamilies Monocotylinae Gamble, 1896 and Dendromonocotylinae Hargis, 1955 (Monogenoidea: Monocotylidae). J. Zool., Lond. 153: 381-422.

Accepted 25 February 2004 